\title{
LOW COST CONSTANT - HEAD DRIP IRRIGATION EMITTER FOR CLIMATE CHANGE ADAPTATION IN NIGERIA: ENGINEERING DESIGN AND CALIBRATION
}

\author{
A. Sobowale ${ }^{1,}{ }^{*}$, A.M. Omotayo², J. O. Olobashola3 ${ }^{3}$ P. Abdulsalaam-saghir ${ }^{4}$, K. Elemo5, \\ B. Badu-apraku6, M. Oladapo ${ }^{7}$ and L. Omonayajo ${ }^{8}$
}

Email addresses:1sobowalea@funaab.edu.ng,2akinjuly@yahoo.com,3subtle009@yahoo.com

4petrajib@yahoo.com, 5 kehindeelemo49@gmail.com,6b.badu-apraku@cgiar.org,7latundeladapo@yahoo.com 8 joeshola@gmail.com

1,8 Dept of Agricultural and Bioresources Engineering, Fed. Univ. of Agriculture, Abeokuta, Ogun State. NiGERIA

2,3 Institute of Food Security, Env. Res. \& Agric. Res., Fed. Univ. of Agriculture, AbEokuta, Ogun StATE. NiGERIA 4 Dept of Agricultural Extension and RuRal Development, Fed. Univ. of Agriculture, AbEokuta, Ogun State. Nigeria 5 Department of Plant Physiology and Crop Production, Fed. Univ. of Agriculture, Abeokuta, Ogun State. Nigeria 6 InTERNATIONAL InSTITUTE OF TROPICAL Agriculture (IITA), IBADAN, Oyo STATE. NIGERIA

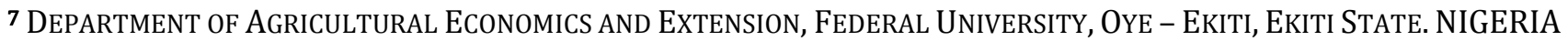

\begin{abstract}
A low cost constant - head emitter for drip irrigation was developed using cheap and readily available materials as a substitute for the imported drip emitters which deter the adoption of drip irrigation in sub-Saharan Africa (SSA). The emitter was calibrated at both laboratory scale and on the field. The drip system comprises of abarrel, sub-main line, lateral lines, tubes and emitters, it can irrigate140 crop stands and can be extended to 560 stands. The emitters produced a mean discharge and emission uniformity (Eu) of $1.601 / \mathrm{hr}$. and $74 \%$ respectively; while the calibrated manufacturer's coefficient of variation and distribution uniformity of discharge were 0.098 and $86.3 \%$ respectively. The system operates under low pressure ( $87.9 \mathrm{mbar}$ ) and can deliver the daily crop water requirement of a crop like maize in 20 minutes; the overall system performance based on field calibration is generally satisfactory and show potential for improvement when compared with global standards for drip systems. The system's low cost of N15, 870 (\$79) gives it an edge over existing locally developed drip systems, the low technology and the use of locally available materials coupled with the water savings will enable famers to adapt to the impact of climate change in sub-Saharan Africa through the production of high value crops in the dry season.
\end{abstract}

Keywords: Drip Irrigation; Food security, Climate change; Adaptation and Cost

\section{INTRODUCTION}

The climate change phenomenon has been reported to have severe impact on agricultural production systems, especially in Sub - Saharan Africa (SSA). With the changes in the climate regime, SSA is expected to experience drier climate which will greatly impact the rain fed agricultural production system widely practiced in the region [1]. According to [2], the influence of climate change will also lead to increased variability of freshwater resources which will culminate into surface water scarcity, groundwater depletion and environmental degradation with consequent effect on food security in the region. The Food and Agricultural Organization of the United Nations reported that almost 1 billion people are undernourished worldwide, particularly in SSA and Asia. In developing countries, even if agricultural production doubles by 2050 , one person in twenty still risks being undernourished - equivalent to 370 million hungry people, most of whom will again be in Africa and Asia[3]. Such growth implies that agriculture will remain an engine of growth, vital to 
economic development, environmental services and central to rural poverty reduction.

The above scenario points to the need especially in SSA countries to adopt production systems which will produce more crop yield per drop of water used in order to adapt to the menace of climate change. Drip irrigation has been reported as the most efficient method of irrigating crops; while sprinkler systems are around $75-85 \%$ efficient, drip systems typically are $90 \%$ or higher [4]. The high efficiency of drip irrigation results from two primary factors, first is that the water infiltrates into the soil before it can evaporate or run off and secondly, because water is only applied to where it is needed (at the plant's roots) rather than sprayed everywhere. The adoption of the drip system in SSA has been hampered by its perceived complexity, high system cost and the low perception of its capability in comparison with the existing irrigation systems.

The adoption of drip irrigation is abysmally low in Nigeria; apart from the total lack of local production of the system, farmers depend too heavily on rain fed systems for their cultivation. The use of surface irrigation and sprinkler systems has however been in practice in the country since 1925; from 1970 - 1990, the country witnessed massive development of surface irrigated schemes [5] without any consideration for the more efficient drip irrigation system. In recent time, a number of research efforts has however been directed at promoting drip irrigation systems for dry season farming in Nigeria [6][7][8], the drip systems used in these studies were imported into the country and not readily available to local farmers for adoption. Concise efforts directed at local design and production of drip systems using locally available materials was pioneered by [9] with the development of a continuous flow drip system using medical infusion sets as emitters; [10] also advanced a simple gravity drip system using polyvinyl chloride pipes with equally spaced holes as line emitters; [11] developed a drip system using micro tubes as emitters, [12] also explored the use of Bamboo pipe and medi-emitters in a simple gravity drip system while [13] presented the possibility of using simple plastic drinking straw as emitters. All these efforts yielded promising results within their operating environment and design objectives, the developed systems however fell below the expectation of low cost and ease of adoption by local farmers for medium and large scale cultivation, their commercial production and economic viability are also cause for concern. These efforts deserve a great deal of commendation; however, there are still some unexplored possibilities in cheaper and more efficient components for the drip system. The emitter discharge ranges are still showing indications that the existing systems are limited to a small range of crops, and the farmland sizes where they are applicable may be limited to small land holdings. This research was aimed at developing a low cost constant - head drip irrigation emitters using low technology and locally available materials for climate change adaptation in sub - Saharan Africa.

\section{MATERIALS AND METHOD}

\subsection{Materials}

The following materials were used for the fabrication of the constant - head emitter: $0.05 \mathrm{~m}$ diameter Polyvinyl chloride (PVC) pipe, $0.003 \mathrm{~m}$ thick PVC plate, $0.001 \mathrm{~m}$ drip orifice, $0.01875 \mathrm{~m}$ PVC pipe, 202 litres PVC drum, $0.0125 \mathrm{~m}$ PVC pipe, $0.025 \mathrm{~m}$ back nut, 0.01875 - $0.0125 \mathrm{~m}$ adaptor, $0.0125 \mathrm{~m}$ coupling, adhesive gum, $0.01875 \mathrm{~m}$ valve, $0.01875 \mathrm{~m}$ end cap, $0.0125 \mathrm{~m}$ end cap, infusion needles, tubes and connectors.

\subsection{Design Concept}

The concept underlining the design is to develop a drip irrigation system that is cheap to rural farmers using low cost, readily available materials and adopting low technology which will require no special skills and will be adaptable to local environmental conditions in rural areas. The system should also be able to perform the following:

- Apply water to meet peak crop water requirement

- Maintain application and uniformity efficiencies at optimum levels

- Provide an energy and water efficient system to keep initial capital and operating cost as low as possible

\subsection{Detailed Engineering Design}

Though, drip irrigation systems are best suited for high value vegetable crops, they are adaptable to other type of crops. For the purpose of design, the extra early maize variety (zea mays spp) was chosen as the design crop, with a conventional plant spacing of 0.25 $\mathrm{m}$ (intra row) by $0.75 \mathrm{~m}$ (inter row) with one seed/stand.

\subsubsection{Crop Water Requirement:}

Crop water requirement (CWR) of plants depends on 
many factors viz. temperature, humidity, soil type, wind velocity, growth stage, shade / sun etc. Plants absorb soil moisture and transpire it to the atmosphere during the process of photosynthesis. Water requirement of the plant per day is equivalent to the rate of potential evapotranspiration (PET) per day, the values for reference evapo-transpiration are normally available for particular area at the nearest meteorological observatory.

Using Abeokuta, Nigeria as a design case and considering the fact that CWR depends on growth stageviz. Initial period, crop development, mid-season and late season; each crop stage has its distinct CWR. For the purpose of design, peak CWR was obtained using both CROPWAT $^{\circledR} 8.0$ software and manual calculation as:

$$
\mathrm{CWR}=E T_{o} \times K_{c} \times K_{p} \times A
$$

In (1), $\mathrm{ET}_{\mathrm{o}}$ is reference evapotranspiration, $\mathrm{K}_{\mathrm{c}}$ is crop coefficient, $K_{p}$ is pan coefficient and $A$ is the land area in $\mathrm{m}^{2}$. The meteorological data obtained from the Agromet station of the Federal University of Agriculture, Abeokuta reveal that average $\mathrm{Et}_{\mathrm{o}}=4$ $\mathrm{mm} /$ day for the critically dry months of December, January, February, March and some parts of April, other months in the year receive sufficient rainfall to sustain crop development; average $\mathrm{K}_{\mathrm{c}}$ selected for maize as test crop was 0.84 while selected $K_{\mathrm{p}}$ was 0.7 . Using a crop spacing of $0.25 \mathrm{~m} \times 0.75 \mathrm{~m}=0.1875 \mathrm{~m}^{2}$, $\mathrm{CWR}_{\text {(maize) }}$ (litres/day/plant) $=4 \times 0.84 \times 0.7 \times 0.1875$ $=0.441$ Litres $/$ day $/$ plant

For a test plot size of $25 \mathrm{~m}^{2}$ and a total of 140 maize crop stands,

Total daily water requirement $=0.441 \times 140=61.74$ litres/day

\subsubsection{Emitter chamber:}

Internal diameter $=0.05 \mathrm{~m}$; Length of chamber $=$ $0.08 \mathrm{~m}$

$$
\text { Volume of chamber }=\frac{\pi \mathrm{d}^{2}}{4} \times \mathrm{L}
$$

This yields $157 \mathrm{ml}$.Equation (2) can also be applied for the calculation of the volume for water storage to yield $127 \mathrm{ml}$ when $\mathrm{d}=0.045 \mathrm{~m}$.

Emitter discharge nozzle $=0.001 \mathrm{~m}$ internal diameter (ID)

Emitter inlet connector $=0.0055 \mathrm{~m}$ internal diameter (ID)

\subsubsection{Specification of Emitter Stand:}

The emitter stand was fabricated from a $0.003 \mathrm{~m} \mathrm{PVC}$ plate, white in colour and cut to size as detailed in Figure 1. The orthographic projection of the constant head emitter is also shown in Figure2;

Specification: $a b=a c=b c=0.086 \mathrm{~m}$

$\mathrm{AB}=\mathrm{BC}=\mathrm{AC}=0.101 \mathrm{~m}$

$$
\text { Area of emitter stand, } A=\frac{1}{2} b h
$$

This yields $\mathrm{A}=0.00449 \mathrm{~m}^{2}$.

System design for $25 \mathrm{~m}^{2}$ plot:, Lateral Line specification:, Lateral pipe size $=0.0125 \mathrm{~m}$ internal diameter (ID), Pipe length $=5 \mathrm{~m}$, Lateral pipe spacing on sub- main pipe $=1.5 \mathrm{~m}$, Emitter Spacing on lateral $=0.25 \mathrm{~m}$ (for maize), Design plant spacing (intra row $\mathrm{x}$ inter row) $=0.25 \mathrm{~m} \mathrm{x} 0.75 \mathrm{~m}$ (for single seed/hole), Connecting tube length $=0.375 \mathrm{~m}$ and Internal diameter of connecting tube $=0.004 \mathrm{~m}$ Sub - main line specification:

Sub - main pipe size $=0.1875 \mathrm{~m}$ ID, Pipe length $=5 \mathrm{~m}$, Operating water pressure $=0.85 \mathrm{~m}$ of water $=87.09$ mbar.

\section{Design for reservoir:}

Drum Height $=0.85 \mathrm{~m}, \mathrm{ID}=0.56 \mathrm{~m}$, Volume of water $=$ $0.202 \mathrm{~m}^{3}$ (202 litres), Pressure head at atmospheric condition $=0.85 \mathrm{~m}$ of water $=87.09 \mathrm{mbar}$

Figure 2 shows the schematic diagram and field installation of the low cost drip irrigation system during field calibration and experimentation.
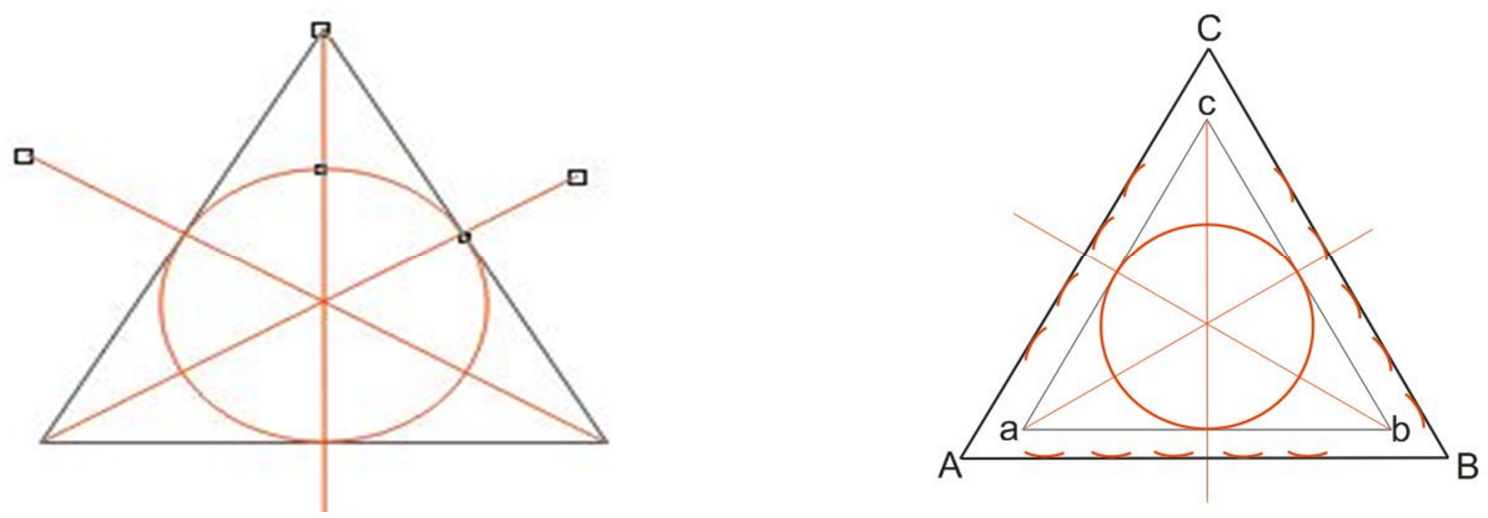

Figure 1a: Geometrical construction of emitter stand 

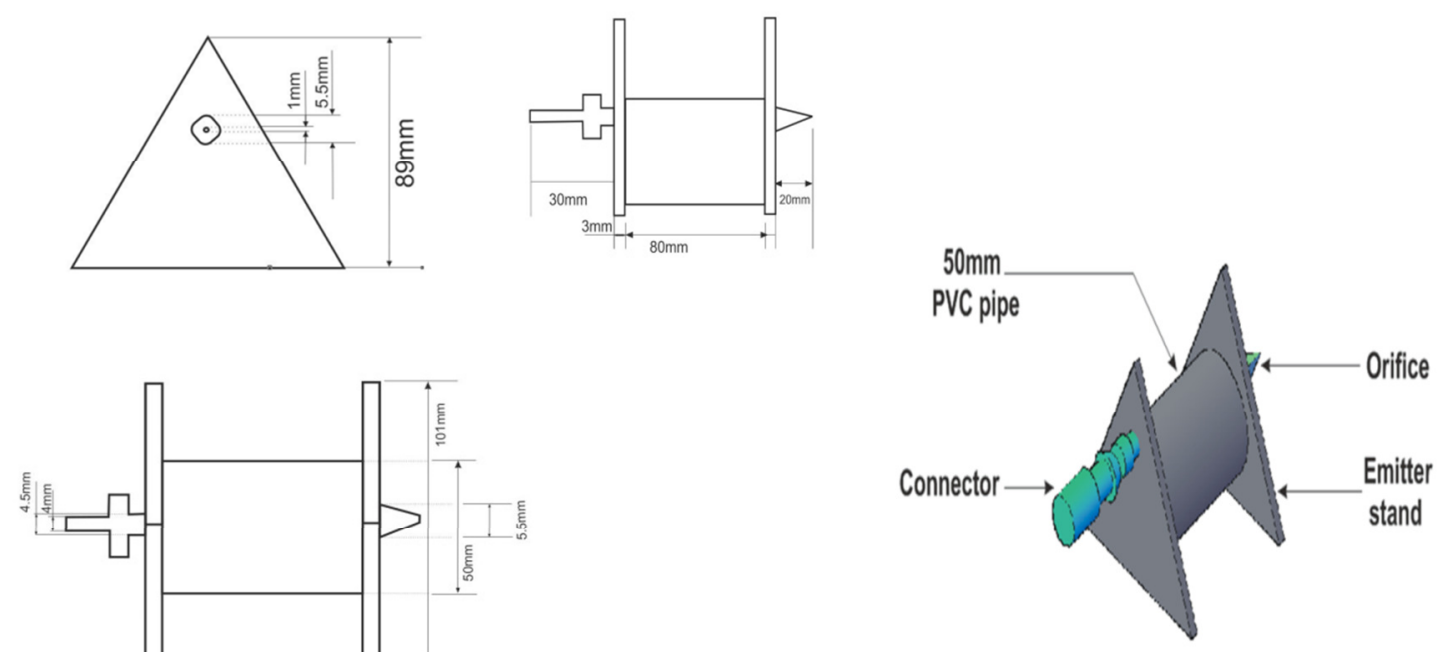

Figure 1b: Orthographic projection and Isometric view of emitter
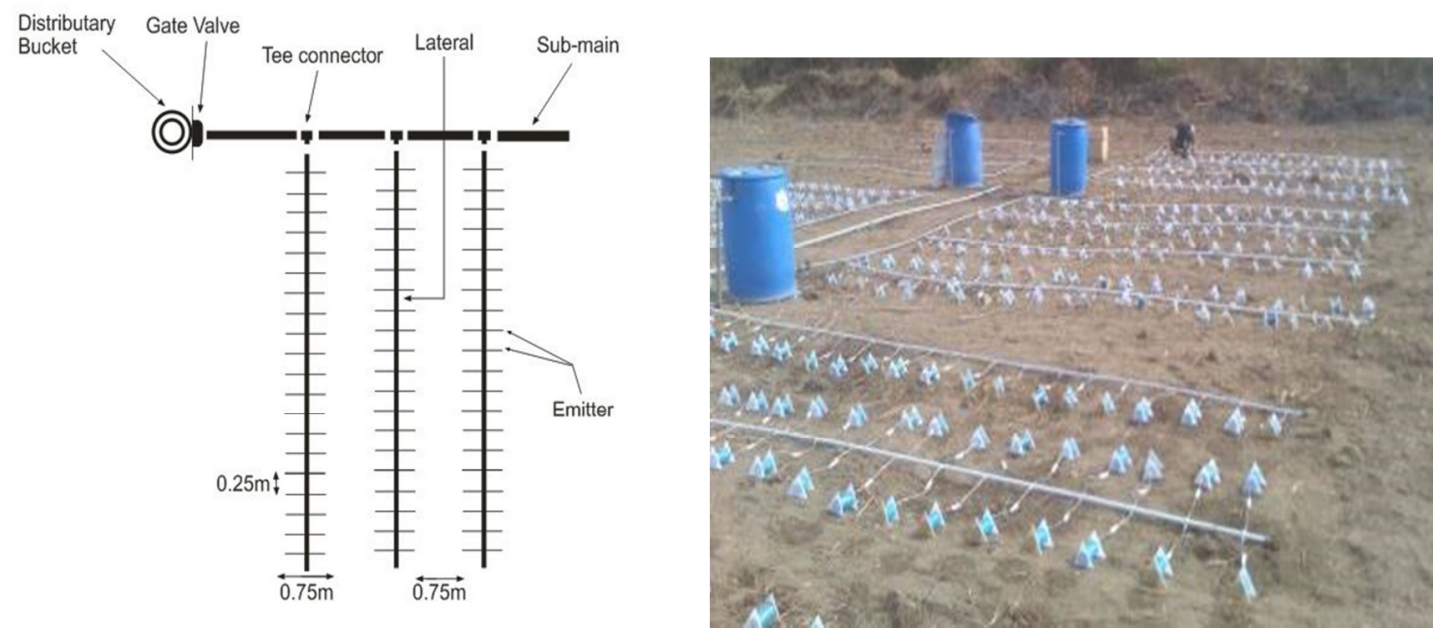

Figure 2: Field layout of low cost drip irrigation system

\subsection{System Configuration and Field Layout}

The emitters were fabricated using $50 \mathrm{~mm}$ OD PVC pipe and $3 \mathrm{~mm}$ plastic plate and a drip orifice. The $0.050 \mathrm{~m}$ PVC pipes were cut to a length $0.080 \mathrm{~m}$, while the plastic plate were cut into a triangular shape of size $0.0101 \mathrm{~m} \times 0.0101 \mathrm{~m} \times 0.0101 \mathrm{~m}$ to serve as the stand for the emitter and to close the ends of the pipe. The plastic plates were drilled to serve as the inlet (0.004 $\mathrm{m}$ ID) and outlet (0.0055 m ID) of the emitter. All joints were fastened together using PVC gum to prevent leakages.

The full system comprises of a 202 litres water barrel as shown in Figure 3, the barrel supplies water to the $0.01875 \mathrm{~m}$ PVC sub - mainline; the flow of water from the barrel to the sub - main line is controlled by an $0.01875 \mathrm{~m}$ gate valve which supply water into four rows of $0.0125 \mathrm{~m}$ PVC lateral lines through reducer tee $(0.01875 \mathrm{~m}-0.0125 \mathrm{~m})$ installed on the sub - main at a spacing of $150 \mathrm{~mm}$ to achieve a plot size of $25 \mathrm{~m}^{2}$. A total of forty emitters were installed on each lateral using a $4 \mathrm{~mm}$ ID tube at a spacing $0.020 \mathrm{~m}$ along the lateral, each lateral was capped with a0.0125 m PVC end cap.

\subsection{Laboratory and field Calibration of Emitter}

The emitter was calibrated in the laboratory to ascertain its performance; water was supplied to the emitter at varied elevation $(1 \mathrm{~m}, 0.80 \mathrm{~m}, 0.60 \mathrm{~m}, 0.40$ $\mathrm{m}, 0.20 \mathrm{~m}$ and 0 ) using a $75 \mathrm{ml}$ container as water reservoir. Emitter flow rate, $Q$ and length of spray, 1 were determined at the different elevations at a constant time, $t$ of 120 s per experimental run; a total of 36 experimental runs were conducted for both closed and open (gravity) system. Field calibration was also carried out using the field layout in Figure 2; a $25 \mathrm{~m}^{2}$ experimental plots in three replicates was used for the field calibration with water supplied by gravity from a 202litres barrel with operating 
pressure of 87.09 mbar ( $0.85 \mathrm{~m}$ of water), emitter discharge on the field was evaluated for the 140 installed emitters; data analysis was carried out using SAS ${ }^{\circledR}$ 9.1.3 software for pertinent field performance parameters such as coefficient of variation of emitter discharge, emission uniformity (Eu), distribution uniformity (DU),Christianson's uniformity coefficient (CUC) and Statistical uniformity coefficient (Us) as follows:

Coefficient of variation of emitter discharges, CV calculated as,

$$
C V=\frac{S d_{q}}{Q_{a v}}
$$

Where $\mathrm{Sd}_{\mathrm{Q}}$ and $\mathrm{Q}_{\mathrm{av}}$ are the standard deviation and average of emitter discharges respectively.

Emission uniformity was calculated from,

$$
E u=100\left(1.0-\frac{1.27 C v}{\sqrt{N_{e}}}\right) \frac{Q_{\min }}{Q_{a v}}
$$

where, $\mathrm{Ne}$ is the number of emitters per plant, $\mathrm{Cv}=$ discharge coefficient of variation, $Q_{\min }$ is minimum emitter discharge $(\mathrm{l} / \mathrm{hr}$.) for minimum pressure in the subunit, while $Q_{a v}$ is average emitter discharge, $1 / h r$. for the sub unit

Distribution uniformity, DU calculated as percentages (\%) is given as,

$$
D U=100\left(Q_{l q} / Q_{a v}\right)
$$

Where $Q_{l q}$ is the average emitter discharge $(\mathrm{l} / \mathrm{hr}$.) in the quarter of the field receiving the least water and $Q_{a v}$ average emitter discharge in entire field.

Christianson's Uniformity Coefficient, CUC also calculated as a percentage (\%) is given as,

$$
C U C=100\left(1-\frac{S d_{Q}}{Q_{a v}}\left(\frac{2}{\pi}\right)^{0.5}\right)
$$

Where $S d_{Q}$ and $Q_{a v}$ are the standard deviation and average of emitter discharges respectively.

Statistical uniformity coefficient, $\mathrm{U}_{\mathrm{s}}$ was calculated as,

$$
U_{s}=100\left(1-\frac{S d_{q}}{Q_{a v}}\right)
$$

Where $S_{Q}$ and $Q_{a v}$ is the standard deviation and average of emitter discharges respectively

Using maize as a test crop, duration of irrigation using the emitter will be

$$
\text { Irrigation time (hrs/day) }=\frac{\mathrm{CWR}_{\text {maize }}}{\mathrm{WAR}}
$$

Where CWR is the crop water requirement in litres/day for maize while WAR is the water application rate in litres/hr.

\section{RESULTS AND DISCUSSION}

The constant - head drip emitter developed for climate change adaptation is presented in Figure 2, the emitter was fabricated using readily available materials that are low cost and can easily be purchased locally. The system layout is also shown in Figure 3.

\subsection{Result of Emitter Calibration}

The laboratory calibration test carried out on the emitter revealed an optimum performance which was found to be in consonance with existing standards in the design of drip irrigation systems. Figure 4 shows the performance of the emitter when subjected to a closed water system; it specifically shows the relationship between the pressure head of water (elevation) and emitter discharge/length of water spray. The system revealed a positive correlation between elevation and emitter discharge rate $\left(r^{2}=0.9434\right)$, this is an indication that operating the system at higher elevation increases the emitter discharge rate; this has direct implications on the type of crops that can be grown using the system, traditionally, drip system are used for the production of high value crops such as vegetables, Tomato, Egg Plant, Onion, Cabbage, Cauli-Flower, Garlic, Watermelon, Cucumber, Lettuce etc. An important observation was that the emitter did not release water when the elevation of the water reservoir was at 20 $\mathrm{cm}$ and at datum; this implied that the minimum elevation (pressure head) for water release in a closed system is $40 \mathrm{~cm}(\mathrm{Q}=0.77 \mathrm{l} / \mathrm{hr}$.). The result also showed that the emitter spray length is also directly correlated with reservoir elevation $\left(r^{2}=0.955\right)$ with spray length ranging between $11.7-28.3 \mathrm{~cm}$ for the pressure heads evaluated.

The open system however showed remarkable improvement over the closed system simply because the system was under the force of gravity. Emitter discharge was achieved at $20 \mathrm{~cm}$ above datum and even at datum with an average discharge of 1.25 and $0.67 \mathrm{l} / \mathrm{hr}$. respectively. There was a better correlation between reservoir elevation and emitter discharge rate $\left(r^{2}=0.9568\right)$ indicating a better performance. Stemming from the foregoing, a gravity system is more appropriate for the fabricated emitter, this is advantageous to the rural farmers because of the elimination of the need for pumping. The gravity system also gave a higher length of spray with a range of $5-37.7 \mathrm{~cm}$; this has direct implications for crop spacing and emitter placement on the field. 


\subsection{Performance Characteristics of Constant - Head Drip Emitter}

The field installation of the developed constant - head emitter is shown in Figure3; the system was installed on a land with predominantly sandy soil and land slope ranging between $2-3 \%$, water filtration was achieved at the inlet of the sub - main line using a cloth mesh of very small opening wound and forced into the inlet pipe, the inlet pipe was also installed at a height of $100 \mathrm{~mm}$ above the reservoir bottom to give room for sedimentation of dissolved solids that may be in the irrigation water.

The performance characteristics of the drip system on the field is presented in table 1; result of trials with a test crop (extra early maize) will be presented in the second part of this paper, this is because the uniformity of crop yield within the lateral length is very important in determining system efficiency.

The field test showed an average emitter discharge of $1.6 \mathrm{l} / \mathrm{hr}$. for the 140 emitters installed with a standard deviation of 0.154 , the calculated manufacturer's coefficient of variation $\left(\mathrm{C}_{\mathrm{v}}\right)$ was $0.098(9.8 \%)$ which revealed that the system performed marginally according to ASAE standards for drip systems (EP405.1). This imply that the system could be further improved to give higher rating as shown in Table 2; when compared with other locally fabricated drip systems, the constant - head emitter was found to perform better than the one advanced by [13], they reported a $\mathrm{C}_{\mathrm{v}}$ of 0.2 which reveal that their drinking straw emitter has a very large variation in discharge which is unacceptable according to ASAE standards $\left(C_{v}>0.15\right)$ (ASAE, 2003); furthermore, the system cost of $\$ 22,000$ (\$105) per 0.1 ha is not realistic owing to the cost of the system components reported. The cost of investment in the barrel kit of the developed constant - head drip system on the other hand for a 25 $\mathrm{m}^{2}$ plot size was $\$ 15,870$ (\$79) at a current exchange rate of $\$ 210$ to $\$ 1$ (US), further evaluation also revealed that the system can be extended to irrigate up to $100 \mathrm{~m}^{2}$ by raising the barrel to a height of $1 \mathrm{~m}$ above the ground, this will serve 560 maize crop stands. This shows that despite the limitation of marginal $\mathrm{C}_{\mathrm{v}}$, the new system will still perform better. The most important factor militating against the adoption of drip irrigation in SSA has been the capital investment required for system purchase. With this low cost system being advanced, the chances of possible adoption by farmers is higher, however, further research could still make the system cost cheaper.
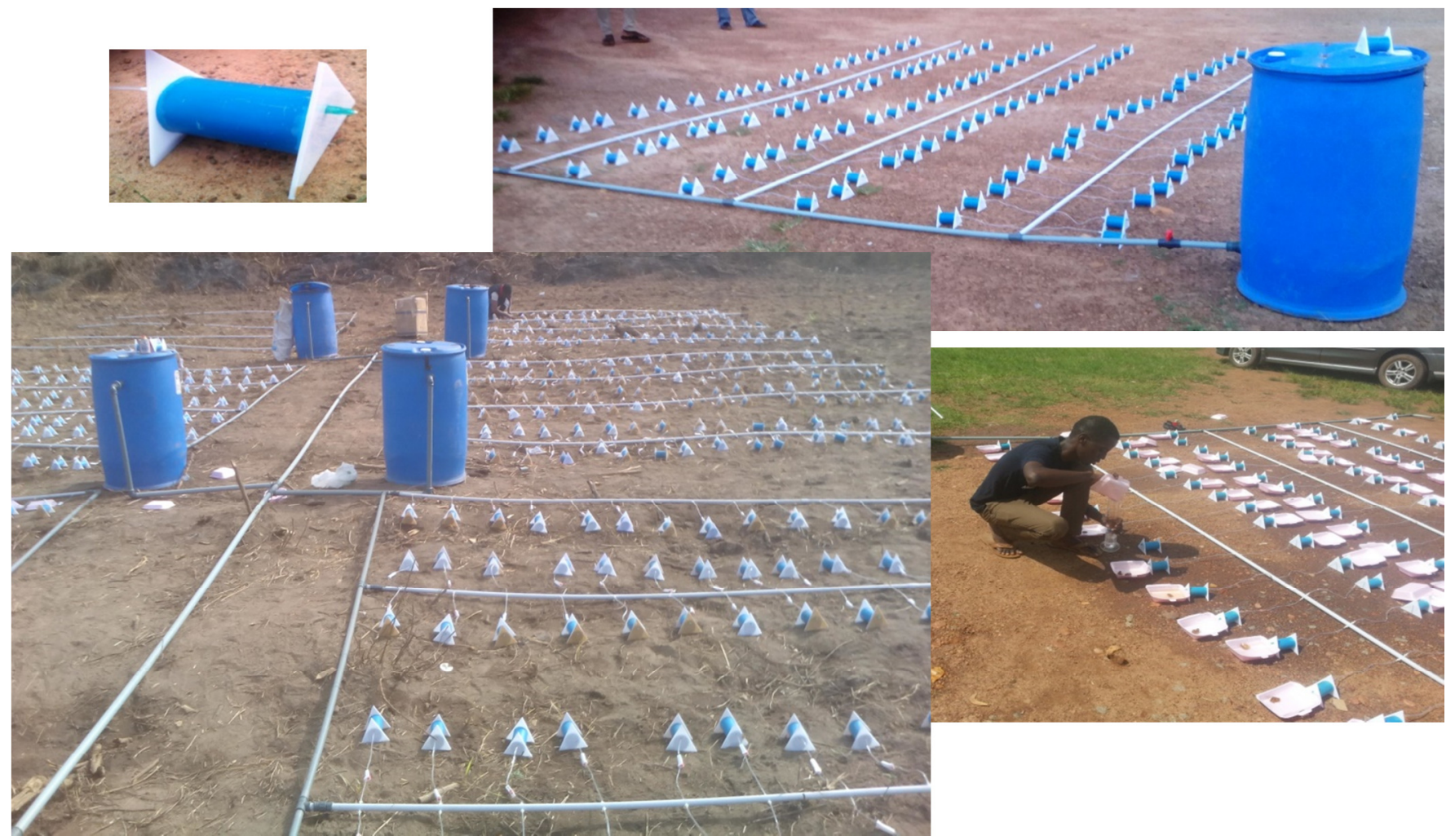

Figure 3: Installation of low cost drip system on the field and discharge measurement 
Table 1: Performance Characteristics of developed Constant - head Drip Emitter

\begin{tabular}{|c|c|c|}
\hline Parameter & Values & Remarks \\
\hline Mean discharge & $1.6 \mathrm{l} / \mathrm{hr}$. & \\
\hline Standard deviation & 0.154 & \\
\hline Discharge Range & $1.20-1.99 \mathrm{l} / \mathrm{hr}$. & \\
\hline Coefficient of Variation, CV & $0.098(9.8 \%)$ & ASAE EP405.1 rating - Marginal \\
\hline Emission Uniformity, $\mathrm{E}_{\mathrm{u}}$ & $74 \%$ & Acceptable value but could be improved \\
\hline Distribution Uniformity, DU & $86.3 \%$ & Within acceptable limits \\
\hline $\begin{array}{l}\text { Christianson's Uniformity Coefficient, } \\
\text { CUC }\end{array}$ & $71.2 \%$ & Slightly lower than normal, could be improved \\
\hline Statistical Uniformity Coefficient, Us & $89.5 \%$ & Within acceptable range, best when $>90 \%$ \\
\hline Irrigation Time (maize crop) & $\approx 20$ minutes & $\begin{array}{l}\text { Time effective system, gives room for other } \\
\text { operations }\end{array}$ \\
\hline Operating Pressure & 87.09 mbar & \\
\hline Unit cost (25 $\mathrm{m}^{2}$ test plot) & $\$ 15,870(\$ 79)$ & $\begin{array}{l}\text { land size could be increased to } 100 \mathrm{~m}^{2} \text { if barrel is } \\
\text { raised to } 1 \mathrm{~m} \text { above ground }\end{array}$ \\
\hline
\end{tabular}

Further evaluation of the constant - head drip system revealed emission uniformity of $74 \%$ which shows satisfactory conformity to standard and also shows the promise of further improvement. [9] reported a Christianson's uniformity coefficient (CUC) and distribution uniformity (DU) of $92.3 \%$ and $89.7 \%$ respectively for their continuous flow drip system; the new system being advanced gave a CUC and DU of $71.2 \%$ and $86.3 \%$ respectively, these values are just slightly lower than acceptable ranges according to ASAE standards. The reasons for these observed lower values are probably due to the non-uniformity of the internal diameter of the drip orifice since they were made manually. This can be improved by using a system of manufacture which will allow for a uniform drill diameter for the orifice.

\section{Table 2: Recommended classification of manufacturer's} coefficient of variation $\left(C_{\mathrm{v}}\right)$

\begin{tabular}{rrl}
\hline Emitter type & $\mathrm{C}_{\mathrm{v}}$ range & Classification \\
& $<0.05$ & Excellent \\
Point source & $0.05-0.07$ & Average \\
& $0.07-0.11$ & Marginal \\
$0.11-0.15$ & Poor \\
& $>0.15$ & Unacceptable \\
\hline Line source & $<0.10$ & Good \\
& $0.10-0.2$ & Average \\
& $>0.2$ & Marginal to \\
& Source: $[14]$
\end{tabular}

The medi - emitter as used by [12] seems to perform well, but they did not mention the system cost which will determine whether the objective of reduced cost was realized, the reported $\mathrm{Cv}$ is not accurate because the values given are ratings for line emitters while their emitter is point source emitter. With the use of appropriate criteria, their drip system can only be adjudged "marginal". Going by the discharge ranges obtained from the constant - head emitter, the operating time for the system has been shortened for a test crop like maize in the Abeokuta environ which was used for the design; the 20 minutes obtained for satisfying the peak crop water requirement of maize in the dry season is considered excellent to assist the farmers concentrate on other chores.

Most drip system has an operating time that ranges from $1-24$ hours, this takes most of the farmers time especially for systems that delivers water in drops; the constant - head drip emitter delivers water in streams which are sufficiently infiltrated especially in sandy soils where the risk of water ponding does not occur. The new system is configured to deliver water to the crop daily; allowances could be made to adjust the irrigation interval to less frequently such as once in three days, this will require careful design with serious consideration of the water holding capacity of the soil. A notable problem observed with the emitter was surface tension problems at the drip orifice, this was found to occur when the system is unused for three or more days, air traps are created because of the small internal diameter of the orifice; an easy way to break the air trap is insert a simple office pin into the orifice or to increase the operating pressure slightly.

\section{CONCLUSION}

A low cost constant head emitter was developed for a drip irrigation system for dry season farming using readily available materials and adopting low technology which requires no special skills. The system performed satisfactorily reducing irrigation time to 20 minutes for maize crop; the gravity system will be able to irrigate 140 crop stands with the possibility of extension to accommodate 560 crop stands by simply raising the barrel to an elevation $1 \mathrm{~m}$ above the ground. 

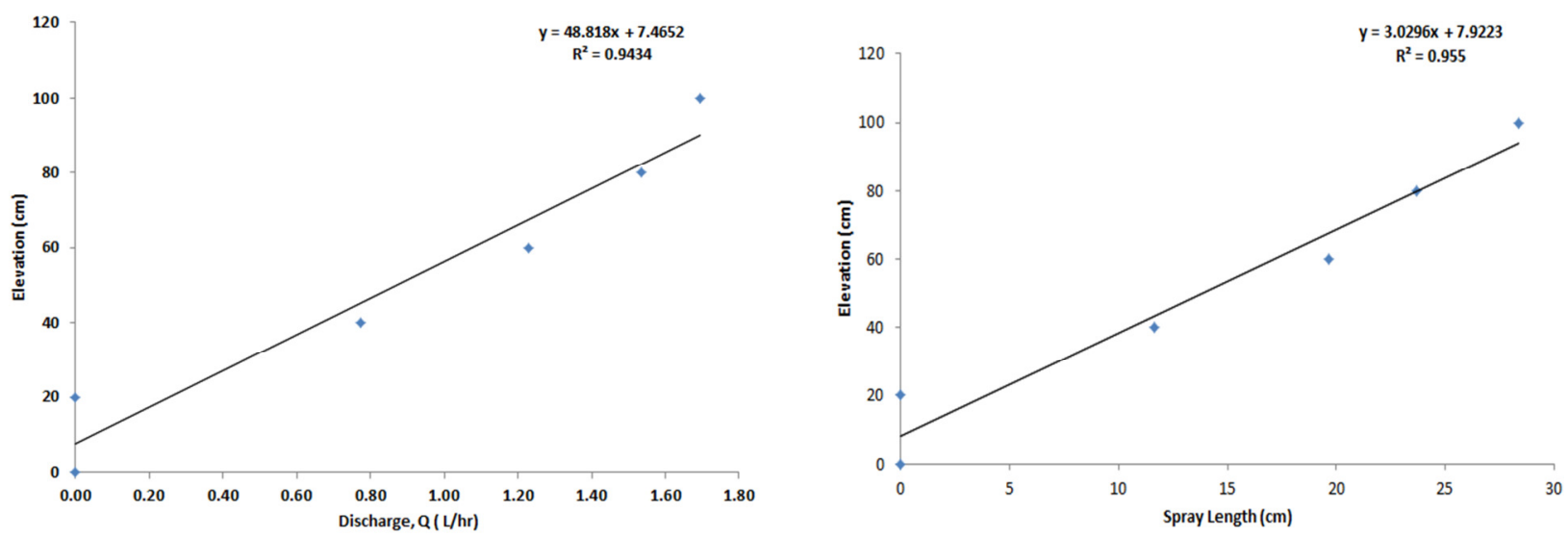

(a) Closed system
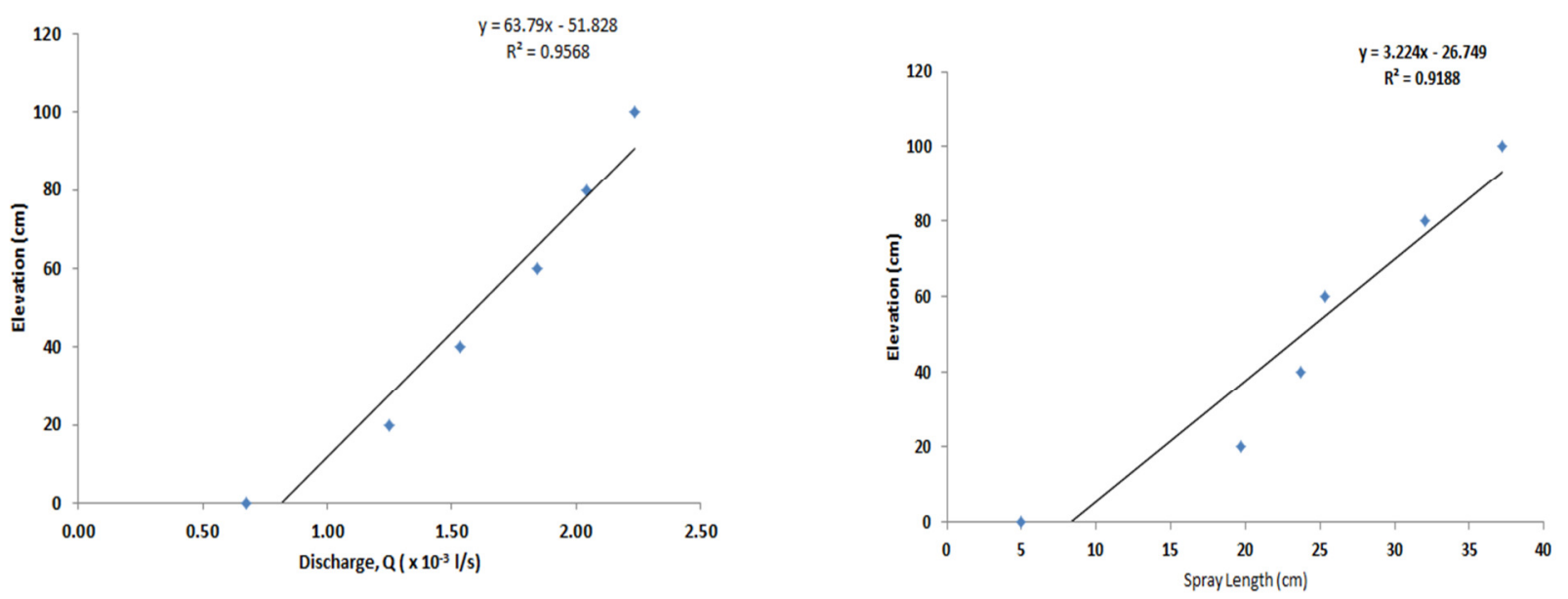

(b) Open system

Figure4: Emitter calibration for pressure head, discharge and length of spray

The system cost was quite low ( 5,870 (\$79)) when compared to other existing local designs. The performance characteristics evaluated have yielded encouraging results in comparison with ASAE standards which is widely accepted in global drip irrigation practice.

\section{ACKNOWLEDGEMENTS}

The authors wish to acknowledge the funding support provided by the West African Agricultural Productivity Programme of the World Bank through grant no. WAAPP/NG/PCO/2.15/01/S.10. Appreciation also goes to Mr. Femi Ayodele for assisting with technical data gathering.

\section{REFERENCES}

[1] IPCC (2014). Climate change 2014: Impacts, Adaptation and Vulnerability. Contribution of working group II to the fifth assessment report of the intergovernmental panel on climate change. Cambridge University Press, UK and New York, USA.
[2] Sobowale, A., Ramalan, A.A., Mudiare, O.J. and Oyebode, M.A. (2015) Groundwater Recharge Studies in irrigated lands in Nigeria: Implications for basin sustainability. Sust. Water Qual. Ecol., http://dx.doi.org/10.1016/i.swaqe.2014.12.004 Elsevier Publishers, UK.

[3] FAO (2011). The state of the world's Land and water resources for food and agriculture: Managing systems at risk. Food and Agricultural Organization of the United Nations, Rome, Italy. http://www.fao.org/nr/solaw/ (assessed on 12/02/2015).

[4] Polak, P., Nanes, B. and Adhikari, D. (1997) A Low Cost Drip Irrigation System for Small Farmers in Developing Countries'. J. American Water Res. Ass., 33(1): $119-124$.

[5] Oriola, E. O. (2009): A Framework for Food Security and Poverty Reduction in Nigeria. European Journal of Social Science. Vol. 8 (1)132-139.

[6] Ewemoje, T.A., Lateef, S.A., Afolayan, S.O. (2006). Performance Evaluation of Drip Irrigation System Using Sweet Corn. Journal of Applied Science, Engineering and Technology Vol. 6 (1) 16 - 21. 
[7] Odubanjo, O. O., Olufayo, A. A. and Oguntunde, P. G. (2011). Water Use, Growth, and Yield of Drip Irrigated Cassava in a Humid Tropical Environment. Soil \& Water Res., 6 (1): $10-20$.

[8] Afolayan, S.O., Ogedengbe, K.O., Lateef, S.A., Akintola, O.A. and Oladele, O.J. (2014) Response of tomato (LycopersiciumLycopersicun, CVUC82B) to drip irrigation and planting condition. African Journal of Agricultural Research, 9(20): 1543 - 1549.

[9] Mofoke, A. L. E., Adewumi, J. K., Mudiare, O. J. and A. A. Ramalan (2004) Design, construction and evaluation of an affordable continuous-flow drip irrigation system, Journal of Applied Irrigation Science, 39 (2): 253 - 269.

[10] EdogaR.N. and EdogaM.O. (2006): Design of drip irrigation set for small vegetable gardens. Not. Bot. Hort. Agrobot. Cluj, 34: 134 - 139.

[11] Akinro, A. O., Olufayo, A. A. and Oguntunde, P. G. (2009). Design, construction and performance evaluation of a drip irrigation system for plantain (Musa, spp. AAB) production in a tropical environment of Western Nigeria. ZeitschriftfürBewässerungswirtschaft, 44 (2) 159 176.

[12] Awe G. O. and Ogedengbe. Kola (2012) Performance Evaluation of Bamboo (Bambusa Vulgaris, Schrad)Pipe and Medi-Emitter in A Gravity-Flow Drip Irrigation System. International Journal of Agriculture and Forestry, 1(1): 9 - 13.

[13] Umara, B.G., Manasseh A.D., Umaru, A.B. and Sadiq A. A. (2012) Potentials of Plastic Drinking Straw as Emitters in Micro Irrigation Drip System Component, Australian Journal of Basic and Applied Sciences, 6(13): $51-56$.

[14] ASAE, (2003) Design and Installation of Micro irrigation Systems. American Society of Agricultural Engineers, ASAE EP405.1, pp. 6. 